\title{
Influence of fiber content on mechanical, morphological and thermal properties of kenaf fibers reinforced poly(vinyl chloride)/thermoplastic polyurethane poly-blend composites
}

\begin{abstract}
Kenaf (Hibiscus Cannabinus) bast fiber reinforced poly(vinyl chloride) (PVC)/thermoplastic polyurethane (TPU) poly-blend was prepared by melt mixing method using Haake Polydrive R600 internal mixer. The composites were prepared with different fiber content: $20 \%, 30 \%$ and $40 \%$ (by weight), with the processing parameters: $140{ }^{\circ} \mathrm{C}, 11 \mathrm{~min}$, and $40 \mathrm{rpm}$ for temperature, time and speed, respectively. After mixing, the composite was compressed using compressing molding machine. Mechanical properties (i.e. tensile properties, flexural properties, impact strength) were studied. Morphological properties of tensile fracture surface were studied using Scanning electron microscope (SEM). Thermal properties of the composites were studied using Thermogravimetric Analyses (TGA). PVC/TPU/KF composites have shown lower tensile strength and strain with increase in fiber content. Tensile modulus showed an increasing trend with increase in fiber content. Impact strength decreased with increase in fiber content; however, high impact strength was observed even with $40 \%$ fiber content $(20.2 \mathrm{~kJ} / \mathrm{m} 2)$. Mean while; the $20 \%$ and $30 \%$ fiber contents showed higher impact strength of $34.9,27.9 \mathrm{~kJ} / \mathrm{m} 2$; respectively. SEM showed that there is poor fiber/matrix adhesion. Thermal degradation took place in three steps. In the first step, composites as well as the matrix had a similar stability. At the second step, matrix showed a slightly better stability than the composites. At the last step, composites showed a better stability than the matrix.
\end{abstract}

Keyword: Natural fiber composites; Kenaf bast fibers; Poly(vinyle chloride)/thermoplastic polyurethane poly-blend; Mechanical properties; Scanning electron microscope; Thermal properties 